\title{
PHOTOBIOSTIMULATION AS A FUNCTION OF DIFFERENT WAVELENGTHS
}

\author{
Rachel L ubart, Ph.D. . ", H arry Friedmann ${ }^{*}$ and R.onit L avie \\ 'D epartment of Physics, Bar-Ilan U niversity, Ramat-G an 52900, Israel \\ "D epartment of Chemistry, Bar-Ilan U niversity, Ramat-G an 52900, Israel.
}

In the current study we compare the effect of different light sources in the visible and near infra-red (IR) range on cell stimulation. It is obvious that in order to interact with the living cell, light has to be absorbed by intracellular chromophores. In a search for chromophores responsible for photobiostimulation, endogenous porphyrins, mitochondrial and membranal cytochromes were found to be suitable candidates, as they possess absorption bands in the visible and near I.R. ranges. The above-mentioned chromophores are photosensitizers that generate reactive oxygen species (ROS) following irradiation. In our opinion the first step in photobiostimulation might be ROS formation. To confirm ROS formation by various light sources, we used the electron paramagnetic resonance (EPR) associated with spin trapping techniques. All wavelengths used (360, 630, 660, 830 nm), including a broad band in the visible range (400-800 $\mathrm{nm})$, stimulated hydroxyl radical formation in sperm cells. Measuring the amount of $\mathrm{OH}$ radicals as a function of the irradiating wavelength shows that shorter wavelengths might be more effective on the cell than longer ones.

Key words: Photobiostimulation, ROS, L aser Therapy, W avelength

\section{Introduction}

A large number of reports document significant positive effects of low energy laser (LEL) radiation on biological systems at the biochemical level. And many patients who responded favorably to LEL therapy are among those who did not respond to standard medical treatments. Various wavelengths (wl) in the visible and near IR are being used in the laboratory and in the clinic for activating the cell. The most common light source for photobiostimulation is the He-Ne (632nm) laser, but many other lasers such as Ar+(488nm), G aAlAs-diode-laser (805nm) and light emitting diodes (660, 780, 830 and 904nm) are successfully used as well.

In the current study we wanted to assess whether the cell responds differently to various wl in the visible range. Because we believe that the first step in photobiostimulation is ROS formation, we estimated the amount of ROS in irradiated cells as a function of the irradiating wl.

Unfortunately, the detection of ROS in biological systems is not simple because of their very short lifetime. An indirect way of measuring ROS is by using a probe molecule, which reacts with the ROS to give a long-life product that may be detected spectroscopically. For example, 9,10 dimethylanthracene (D MA) serves as a molecular trap for ${ }^{1} \mathrm{O}_{2}$ [1]. Another example of this approach is the EPR spin trapping technique. The addition of an appropriate diamagnetic compound called a spin trap to a certain ROS results in a long-life secondary free radical, called a spin adduct, which may be detected by the EPR technique [2]. In this study we have followed hydroxyl radical formation in irradiated sperm cells as a function of the wl, using the EPR spin trapping technique.

\section{Materials and Methods}

EPR measurements:

We used 5,5 dimethyl-1-pyrroline-N-oxide (D MPO) to trap the hydroxyl radicals. D MPO $(0.02 \mathrm{M})$ was added to 106 107 bovine sperm cells/ $\mathrm{ml}$ in a 96 multiwell dish and the cells were irradiated with various light sources. Then, 100 $\mathrm{ml}$ of the cell culture was drawn with a syringe into a gaspermeable teflon capillary (Zeus Industries, Raritan, NJ), of 0.032" inner diameter, $0.015^{\prime \prime}$ wall thickness, and $15 \mathrm{~cm}$ length. Each capillary was folded twice, inserted into a narrow quartz tube which was open at both ends, and placed into the EPR cavity. The EPR spectra were recorded on a Bruker ER 100d X-band spectrometer. The microwave of the EPR was set at $9.67 \mathrm{G} \mathrm{Hz}$ and the power at $20 \mathrm{~mW}$. Modulation frequency and modulation amplitude were 100 $\mathrm{KHz}$ and $1 \mathrm{G}$ respectively, and the swept width was $65 \mathrm{G}$. Time constant (TC) was $655 \mathrm{~ms}$ and measurements time, $168 \mathrm{~s}$.

\section{Irradiation}

For the illumination we used: a) A VL-206BL light source emmitting UVA light at $320-400 \mathrm{~nm}$ with a maximum at $360 \mathrm{~nm}$, the irradiance being $1.5 \mathrm{~mW} / \mathrm{cm}^{2}$ and time of irradiation $1 \mathrm{~min}$. b) An He-Ne laser (632nm), $2 \mathrm{~mW} / \mathrm{cm}^{2}$ for 5 min c) A multiwave band $(400-800 \mathrm{~nm})$ centered at a 
$600 \mathrm{~nm}$ light device, $40 \mathrm{~mW} / \mathrm{cm}^{2}$ for $4 \mathrm{~min}$ d) A $660 \mathrm{~nm}$ light emmitting diode $10 \mathrm{~mW} / \mathrm{cm}^{2}$ for $7 \mathrm{~min}$ e) A $830 \mathrm{~nm}$ light emmitting diode (Lasotronic), $26 \mathrm{~mW} / \mathrm{cm}^{2}$ for $9 \mathrm{~min}$.

\section{Results}

Irradiation of sperm cells with visible or UVA light in the presence of DMPO produces a four-line EPR spectrum with hyperfine splitting $\left({ }_{\mathrm{a}} \mathrm{N}={ }_{\mathrm{a}} \mathrm{H}=14.9 \mathrm{G}\right)$ characteristic of a DMPO-OH spin adduct. In Fig. 1, an example of an EPR spectra of D MPO-OH before and after illumination of sperm cells with a $830 \mathrm{~nm}$ diode laser $26 \mathrm{~mW} / \mathrm{cm}^{2}$, for 9 min is depicted.

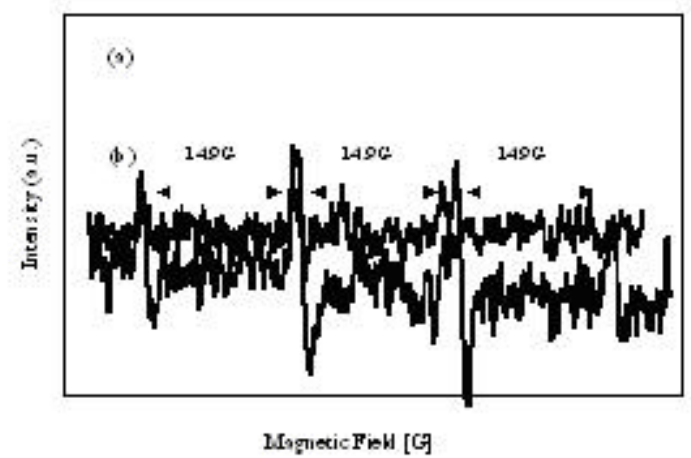

Fig 1: E PR spectra of sperm œlls, (a) Before irradiation. (b) A fter 9 min of illunination with $830 \mathrm{~nm}$ diode laser. The spectra parameters were set to: receiver gain $2 * 10^{5}$; sweep width $57 \mathrm{G}$; resolution 2048; conversion time $82 \mathrm{~ms}$; time constant $655 \mathrm{~ms}$; sweep time $168 \mathrm{~s}$; power $20 \mathrm{~mW}$ : number of scan 3; frequency $9.7 \mathrm{G} \mathrm{Hz}$.

The amount of $\mathrm{OH}$ radicals is proportional to the integrated area under the EPR signal. Assuming a linear dependence of the generated hydroxyl radicals on cell number and fluence of the light source, we normalized the first peak area (of the DMPO-OH quartet) to one cell/ $\mathrm{cm}^{2}$ illuminated with an energy dose of $1 \mathrm{~J} / \mathrm{cm}^{2}$. The normalized area for each wl is shown in Figure 2. It can be seen that the $660 \mathrm{~nm}$ diode and the He-Ne laser produce similar amounts of $\mathrm{OH}$ radicals. The broad band visible light device produces half of this amount, and the 830nm light emitting diode produces a very small amount of hydroxyl radicals. As expected, the UVA light generates a huge amount of $\mathrm{OH}$ radicals in comparison with light in the visible range.

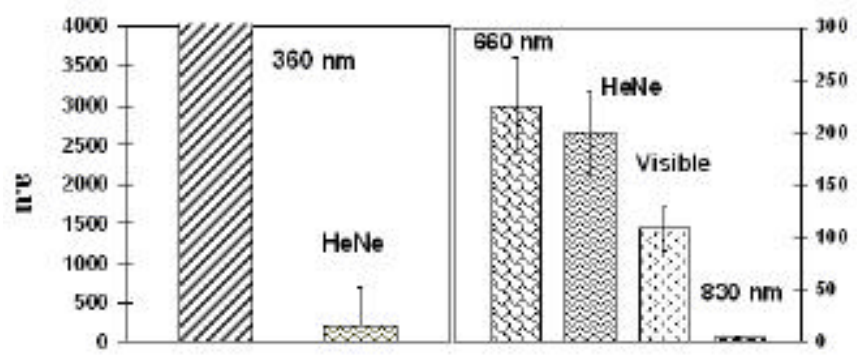

Fig 2: Integrated area of D M PO spin adduct signal normalized to the cell number (cell/ $\mathrm{ml}$ ) and the fluence $\left(\mathrm{J} / \mathrm{cm}^{2}\right)$, for the various illuminating light sources.

39 Laser Therapy Vol. 12

\section{Discussion}

Although the mechanism of light-induced cell activation is still under debate, it is strongly believed that ROS are involved in light-enhanced biostimulation. [3,4,5]

Recent evidence demonstrates that relatively low and controlled concentrations of ROS play an important role in the activation of many cell processes. For example, RO S stimulates fibroblast proliferation [6] and DNA synthesis in the haemopoietic cell line U937. [3] In the case of spermatozoa, ROS such as a superoxide anion, $\mathrm{H}_{2} \mathrm{O}_{2}$, and nitric oxide were found to induce sperm hypercapacitation and acrosome reaction. [7] Suzuki et al. [8] have shown that ROS stimulate signal transduction processes for transcription factor activation, gene expression, muscle contraction and cell growth. Thus, RO S should not be viewed merely as agents that damage cells but may also be mediators of physiological functions and serve as a second messenger.

We strongly believe that small amounts of ROS are being produced in irradiated cells as a result of light absorption by endogenous porphyrins, mitochondrial cytochromes and flavoproteins, $[9,10,4]$ as they possess absorption bands in the visible and near I.R. ranges (Figure 3).

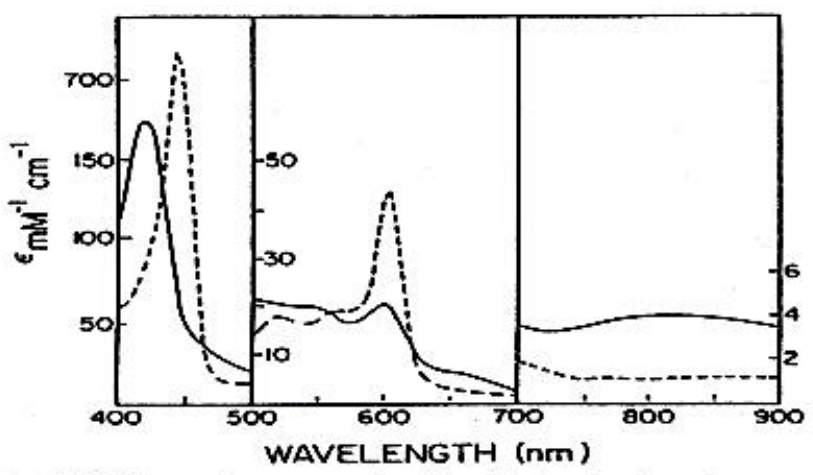

Fig 3: A bsorption spectra of oxidized (-) and reduced (---) cytochrome oxidase.

Since these chromophores are photosensitizers, they create ROS upon irradiation. Karu [11] discusses at length the possibility of Cytochrome $\mathrm{C}$ oxidase as the main photoacceptor for visible and near infrared light. We suggest that NADPH OXIDASE, which has been found to exist in non-blood cells, [12] and possesses a flavoprotein, can also be a target of light. As porphyrin-like molecules have an intense absorption band in the $360 \mathrm{~nm}$ region, and additional bands with decreasing intensity at $502 \mathrm{~nm}$, $540 \mathrm{~nm}, 560 \mathrm{~nm}, 630 \mathrm{~nm}$, and 830nm, (Figure. 3), we expected all these wl to stimulate ROS formation, the shorter wl being more effective. To follow RO S formation in irradiated sperm cells we use the EPR spin trapping 
technique. In the past we have succeeded in detecting singlet oxygen, superoxide anion, and hydroxyl radicals in various irradiated cell cultures. [13,14,15]. In the present study we have estimated the amount of $\mathrm{OH}$ radicals generated in sperm cells as a function of the irradiating wl, and we found that all wl (used by us) in the UVA and the visible range stimulate $\mathrm{OH}$ radical formation (Figure 2), UVA light being more effective, as expected, from the absorption spectrum of porphyrin-like molecules (Figure 3). The action spectrum in Figure 2 also shows that white light $(400-800 \mathrm{~nm})$ is capable of ROS stimulation, and hence, might be used for photobiostimulation. Supporting our results are those of Sroka et al., [16] who found that the action spectrum of the cellular response determined as the mitotic rate induced by light application of an irradiation of $4 \mathrm{~J} / \mathrm{cm}^{2}$ at an irradiance of $10 \mathrm{~mW} / \mathrm{cm}^{2}$, fits the absorption bands of the respiratory chain components. In addition, the action spectrum of cell adhesion (which plays a regulative role in the wound repair process) correlates with the absorption spectrum of cytochrome a/ a3 [17].

UVA light (which generates high amounts of ROS, Figure 2 ) is known for its damaging effect on cells, but if it is used at a very low fluence, it can stimulate the cell. For example, it has been found that to enhance fibroblast proliferation, $0.6 \mathrm{~J} / \mathrm{cm}^{2}$ of UVA light is needed in comparison to 4 $10 \mathrm{~J} / \mathrm{cm}^{2}$ at $600 \mathrm{~nm}$. [19]

According to our results (Figure 2), the stimulatory effects of near IR light sources (for example, 830nm) would be very small as they generate low amounts of ROS. Surprisingly, there are many positive reports in the literature where the stimulating light is in the near IR region. $[20,21]$ For example, to obtain fibroblast proliferation with a 780nm laser only $0.5 \mathrm{~J} / \mathrm{cm}^{2}$ is needed. [5] It is therefore possible that wl in the far-red region interact with the cell through a different mechanism. Karu [22] and Friedmann [4] have suggested that near IR lasers may activate enzymes, and probably $\mathrm{C}^{\text {a }}$ channels, in the membranes.

When irradiating tissues, the penetration of various wl (going down from near IR to UVA) must obviously be considered. Al Watban et al. [23] studied acceleration of wound healing as a function of the wl, and found that it was not attributed to laser skin transmission. They achieved accelerated wound healing at $442 \mathrm{~nm}$ where the skin transmission is very low, but (according to Figure 3) it is compensated by the high extinction coefficient of this wl.

We conclude that UVA and visible light can either stimulate or harm the cell, depending on the amount of ROS they generate. For each wl the irradiance and the time of irradi- ation has to be assessed in order to get the desired optimal bioeffect.

A ddress correspondence to:

Professor Rachel Lubart

Department of Physics

Bar-Ilan University

Ramat-G an 52900

Israel

Tel: +972-3-5317310

Fax: +972-3-5353298

email: lubart@ physnet.ph.biu.ac.il

\section{References}

1. Gross E, Ehhrenberg B, and Johnson, FM (1993): Singlet oxygen generation by porphyrins and the kinetics of 9,10-dimethylanthracene photosensitization in liposomes. Photochemistry \& Photobiology, 57(5): 808-813.

2. Buettner GR (1987): Spin trapping: ESR parameters of spin adducts. Free Radicals in Biology and Medicine, 3(4): 259-303.

3. Callaghan GA, Riordan C, Gilmore WS, McIntyre IA, Allen JM, and Hannigan BM (1996): Reactive oxygen species inducible by low-intensity laser irradiation alter DNA synthesis in the haemopoietic cell line U937. Lasers in Surgery and Medicine, 19(2): 201206.

4. Friedmann H, Lubart R, Laulicht I, and Rochkind S (1991): A possible explanation of laser-induced stimulation and damage of cell cultures. J Journal of Photochemistry \& Photobiology B: 11: 87-95.

5. Grossman N, Schneid N, Reuveni H, Halevy, S, and Lubart R (1998): $780 \mathrm{~nm}$ low power diode laser irradiation stimulates proliferation of keratinocyte cultures: involvement of reactive oxygen species. Lasers in Surgery and Medicine, 22(4): 212-218.

6. Murrell GA, Francis MJ, Bromley L (1990): Modulation of fibroblast proliferation by oxygen free radicals. Biochemistry Journal, 265:659-665.

7. Aitken RJ, Paterson M, Fisher $H$, Buckingham DW, Van Duim M (1995): Redox regulation of tyrosine phosphorylation in human spermatozoa and its role in the control of human sperm function. Journal Cell Sciences, 108:2017-2025.

8. Suzuki YJ, and Ford JD (1999): Redox regulation of signal transduction in cardiac and smooth muscle. Journal Molecular Cell Cardiology, 31(2): 345-353.

9. aru T. (1988): Molecular mechanism of the therapeutic effect of low-intensity laser radiation. Lasers Life Science, 2:53-74.

10. Tamura M (1993): Non-Invasive monitoring of the redox state of cytochrome oxidase in living tissue 
using near-infrared laser lights. Jpn. Circ. Journal, 57(8): 817-824.

11. Karu TI (1999): Primary and secondary mechanisms of action of visible to near-IR radiation on cells. Journal of Photochemstry \& Photobiology B: Biology. 49:1-17.

12. Meier B, Cross AR, Hancock JT, Kaup FJ, Jones OT (1991): Identification of a superoxide-generating NADPH oxidase system in human fibroblasts. Biochemistry Journal, 275:241-245.

13. Lavie $R$, Shainberg $A$, Friedman $H$, and Lubart $R$. D etection of singlet oxygen in irradiated cell cultures: An EPR study. (2001) (To be published).

14. Lubart R, H. Breitbart H, Y. Sofer Y, and Lavie R. (2001) He Ne irradiation of human spermatozoa: enhancement in hamster egg Penetration. (Accepted for publication in Laser Therapy)

15. O ren D, Lavie R, Charney D S, and Lubart R (2001): Stimulation of reactive oxygen species production in fibroblasts by a traditional antidepressant visible light source. Biological Psychiatry, 49:464-467

16. Sroka R, Scaffer M, Fuchs $C$, Pongratz T, SchraderReichard U, Busch M, Schaffer P, Duhmke E, and. Baumgartner R (1999): Effects on the mitosis of normal and tumor cells induced by light treatment of different wavelengths. Lasers in Surgery and Medicine, 25:263-71.
17. Karu T, Pyatibrat LV, and Kalendo G (2001): Cell attachment to extracellular matrices is modulated by pulsed radiation at $820 \mathrm{~nm}$ and chemicals that modify the activity of enzymes in the plasma membrane. Lasers in Surgery and Medicine, 29:274-81

18. Lubart R, Wollman $Y$, Friedmann $H$, Rochkind $S$, and Laulicht I (1992): Effect of visible and near-infrared lasers on cell cultures. Photochemistry \& Photobiology B: Biology, 12:305-310.

19. Grossman N, Schneid N, Reuveni H, Halevy S, Lubart R (2000): Enhanced proliferation of keratinocyte cultures following low power HeNe laser irradiation. Lasers Life Sciences, 9(2): 111-126.

20. Houghton PE, and Brown JL (1999): Effect of lowlevel laser on healing in wound healing fetal mouse limbs. Laser Therapy, 11(2): 54-70.

21. Shamir MH, Rochkind S, Sandbank J, Alon M (2001): D ouble-blind randomized study evaluating regeneration of the rat transected sciatic nerve after suturing and postoperative low-power laser treatment. Journal Reconstructive Microsurgery, 17(2): 133-7.

22. Karu TI (1989): Photobiology of low-power laser therapy. GmbH, Chur, Switzerland: Harwood Academic Publishers.

23. Farouk AH, and Xing YZ (1999): The acceleration of wound healing is not attributed to laser skin transmission. Laser Therapy, 11(1): 6-10

\section{Join the World}

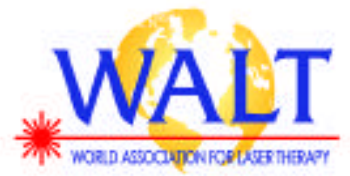

How To Join

(1) Wire transfer your journal subscription and membership fee directly to Kansas Corporate Credit Union, Wichita, Kansas (routing number 301180111). To ensure proper credit, you must instruct Kansas Corporate Credit Union as follows: "Please further credit KUMC Credit Union (assound ABA: 301078731) for deposit in Walt '98 account number $30475 "$ ".

\section{OR}

(2) Send a countersigned Traveler's Check or an international bank draft (made payable to WALT) to the Editor-in-Chief or the Business Manager (see address in this issue of the journal).

OR

(3) Pay by credit card at our Website: [www.walt.nu ]. 